\title{
INVESTIGATION OF PERCEIVED RISK ENCOUNTERED BY ELECTRIC VEHICLE DRIVERS IN DISTINCT CONTEXTS
}

UDC: 629.03

Original scientific paper

https://doi.org/10.18485/aeletters.2021.6.2.4

\author{
Lalit N. Patil ${ }^{1 *}$, Hrishikesh P. Khairnar ${ }^{2}$ \\ ${ }^{1,2}$ Department of Mechanical Engineering, Veermata Jijabai Technological Institute (VJTI), Mumbai, India
}

\begin{abstract}
:
Not only pollution concerns, but also the rising prices of fuel used in conventional vehicles are enforcing people to make use of electric vehicles. In spite of numerous advantages such as pollution-free, noiseless smooth drive; there may be the new possibility of difficulties occurring due to the quiet nature of electric vehicles (EVs). To examine this, it was intended to conduct an extensive questionnaire survey with 398 driver participants to acquire technical data at Mumbai Metropolitan Region (MMR). The analysis used a well-proven driver behaviour questionnaire (DBQ) built on a six-point scale to statistically evaluate driver behaviour responses to perceived risk. This study aims to evaluate the perceived risk encountered by drivers that influence road safety by considering age group, driving experience, and gender. A systematic ANOVA approach was employed to evaluate the significant factors. The results show that the perceived risk is different based on the gender of the driver, especially when parking the vehicle $(p=0.000, F=10.11716>$ Fcrit). The moderate difficulty level for identifying the presence of electric vehicles is present in almost all situations; however, no significant difference was recorded based on gender, age, and driving experience in the rest of the cases. The outcome of the proposed work would be useful while designing the safety policy for electric vehicles.
\end{abstract}

\section{ARTICLE HISTORY}

Received: 24.04.2021.

Accepted: 04.06.2021.

Available: 30.06.2021.

\section{KEYWORDS}

ANOVA, Driver's Perception, Electric Vehicles, Driver

Behaviour, Road Safety

\section{INTRODUCTION AND BACKGROUND}

One of the real challenges of the developed and developing countries is not limited to smooth transportation but ensuring travel with safety in the current era [1]. Indian cities are spreading more rapidly to attain the land requirement of the growing population. In addition to broad urbanization, the growing trend of different forms of pollution has had an effect on human life as it is closely related to the essential breathing quality of air for a human being [2]. Continuous progress and endless attempts are being recorded by the scientific community to improve atmospheric conditions as well as human safety [3-6]. Air pollution, noise pollution, water pollution, and land pollution are the major types of atmospheric pollution. Among all types of pollution, air pollution is the major concern for future [7]. On the other hand, although diesel and petrol prices are rising rapidly, the mobility of people or even the transport of goods cannot be stopped [8]. To tackle this, electric vehicles are coming into picture with great popularity. Key features of electric vehicles include environmental improvement, smooth driving, noiseless driving, a more enjoyable driving experience, and much more. In fact, there are some government policies to promote the use of electric vehicles [9]. While electric vehicles offer significant benefits, certain challenges cannot be ignored. For example, the driving range is limited on the basis of the battery power and the load carried by the vehicle, the periodic battery maintenance is required, and the quiet nature of electric vehicle may be tricky for the pedestrian to 
identify the existence of vehicle on the road $[6,10,11]$.

Globally, more than 1.35 million individuals sacrifice their lives per annum on the world's highways, and as many as 50 million are being injured. Fatalities and injuries caused by road accidents shattered lives and plunge communities into despair (WHO 2020). The reason for such incidence could be driver's ignorance, pedestrian mistakes, driver's fatigue, vehicle brake fault, and many more [12-15]. Human causes have been calculated to be the single or leading contributing factor in nearly $90 \%$ of traffic incidents $[16,17]$. Age is considered as a prominent factor mostly accountable for fatal/accidents [3]. Some researchers reported that there were high numbers of road accidents among young drivers in different countries, as shown in Fig. 1. Among these, the age range '18-25 years' has been a significant contributor to the rise in fatalities. A recent report from World Health Organization revealed that youth with the age group '5-29 years' are the most suffered from road accident fatalities. The driving experience is also a factor to be considered when it comes to related safety and perceived risk $[3,18]$.

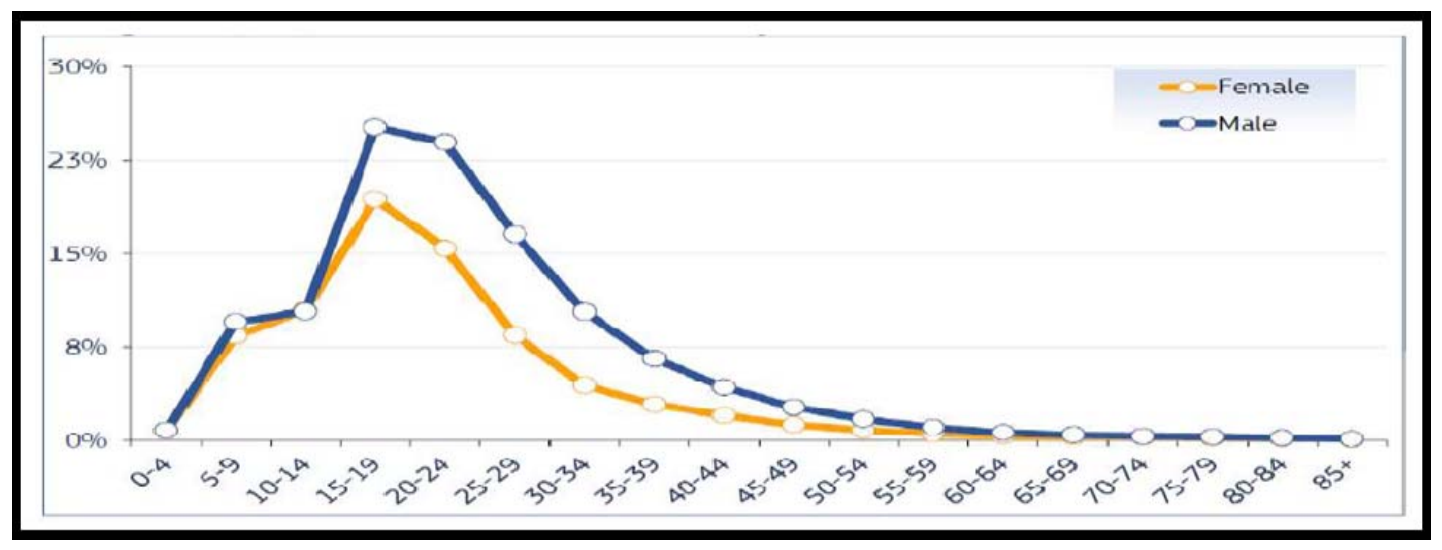

Fig. 1. Percentage of traffic casualties based on age group and gender [19]

Numerous factors related to the possibility of collisions, such as overtaking of moving vehicles, overtaking of motorcycles, passing of other cars, at turning on the road were examined in order to determine perceived risk from driving style and traffic circumstances [20]. Another research found that road accidents are more common when it rains [21]. The report from the EU commission highlights the percentage of accidents based on weather conditions as shown in Fig. 2.

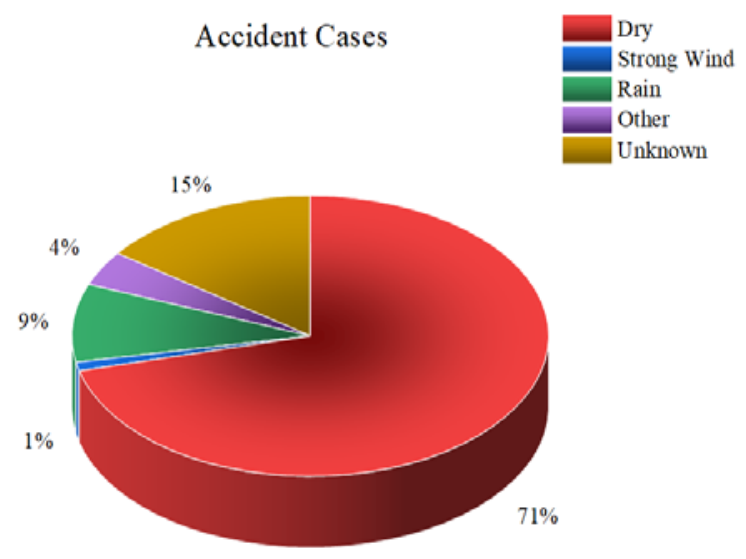

Fig. 2. Accident cases proportion based on weather conditions [19]
Since the electric car is free from noise, it will be difficult for pedestrians to detect the presence of the vehicle on the road. It can even be more difficult for the electric vehicle drivers to guess the engine state for the electric vehicles around the same time at different situations. Recently, the risk to road users due to low noise emissions has been evaluated in order to determine the significance of the risk. The majority of analysts agree that low noise levels in an electric vehicle pose a moderate risk $[6,22]$.

However, as far as the authors are aware, the impacts of low noise for different situations are not much analyzed especially for electric vehicles; that is, evaluation of the risky driver behaviour aspects of an electric vehicle at various situations like starting of the vehicle, while turning on the road, at parking situations, moving on the slope, at city traffic signals where the vehicle is stopped, while running the vehicle at a speed less than 30 $\mathrm{km} / \mathrm{hr}$, during the rainy season, and at hill stations. Earlier research, based on perception of drivers and pedestrians has shown the importance of consideration of low noise level produced by electric vehicles in context of risk $[5,6,11,22]$; hence, it may be argued that electric 
vehicles are difficult to hear for pedestrians as well as drivers from a safety perspective, therefore, this article is intended to evaluate the driver behaviour aspects that influence road safety while considering numerous cases of driving.

The remainder of this article is structured as: Section 2 introduces data collection methods and the design of questionnaires which were implemented to acquire the technical data from participants. Section 3 provides details of the selection of study areas that recognize India's most critical areas that can be considered for the present research study and appropriate methodology adopted for research analysis. Section 4, which points out the results and interpretations of the observations applicable to a systemic study, describes the results based on the perceptions of the driver. Finally, the conclusion is indicated in section 5 based on observations and evaluations carried out in several possible scenarios.

\section{DATA COLLECTION AND DBQ SURVEY}

\subsection{Study Area}

The growing pattern of incidents, especially in the urban area, needs to be tackled in order to improve global safety and human health [23]. Mumbai is India's most populous city and it is known as India's financial and industrial capital. The Mumbai Metropolitan Region is an area composed of Mumbai along with its satellite towns from the state of Maharashtra, India. As the millions of people travel in a day and many of them are pedestrians, continuous incidences/ fatalities have been reported. The city's large population and heavy traffic on the roads may be potential contributors to a variety of incidents
[24]. The rise in pollution along with congestion of traffic is enforcing government to introduce the electric vehicle on road to maintain the state of the atmosphere in urban areas [9]. Since now, several policies had been prepared and implemented by the government of India to control the rise in various pollutions. Since the Indian government announced the National Electric Mobility Mission Plan (NEMMP) 2020, electric vehicles are emergence on the road with great effectiveness [9]. At the same time, the quiet nature of electric vehicle possess new unintentional risk due to the low noise of an electric vehicle [6]. Therefore, it was planned to examine the driver behaviour aspects that influence road safety by EV drivers at Mumbai Metropolitan Region. This research was performed in the cities of the Mumbai Metropolitan Area in the year 2019-2021. It consists of 9 Municipal Corporations (Mumbai, Thane, Kalyan-Dombivli, Navi Mumbai, MiraBhayandar, Bhiwandi-Nizampur, Ulhasnagar, Vasai-Virar, Panvel) covering a total area of 6640 square $\mathrm{km}$.

\subsection{Participants}

The reason for choosing Mumbai city for the analysis was the majority of incidents observed from the Mumbai region as shown in Fig. 3. The sizes of the samples having 398 drivers are considered based on the Slovin's formula. Initially, we informed participants about our study (purpose of research) so that they can react in a correct manner without fear in their minds. Also, it was explained that their response will be processed anonymously to record the results of the actual perspective with regards to EV. The social and demographic characteristics of drivers (participants) are shown in Fig. 4.

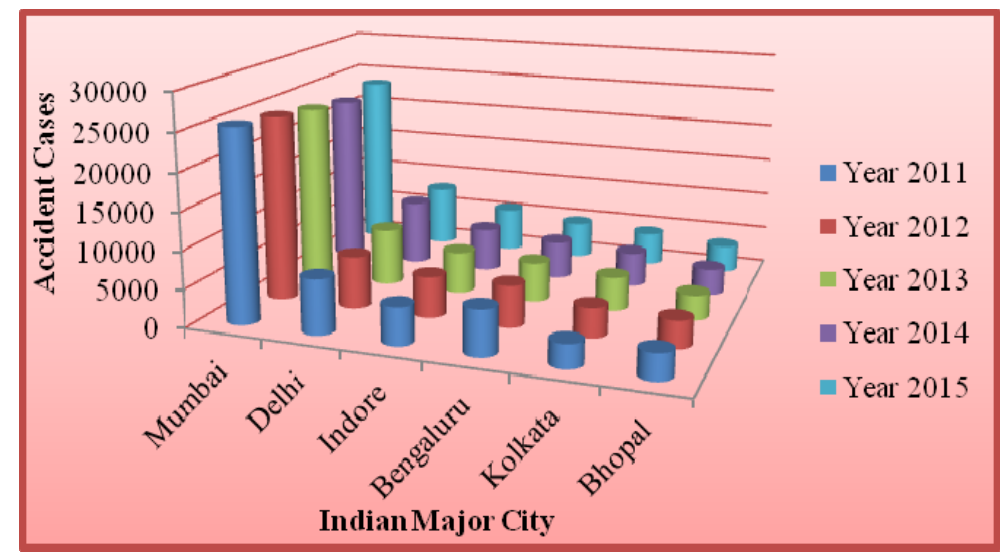

Fig. 3. Year wise trend of accidents at major cities in India (Source: Open Government Data Platform India) 


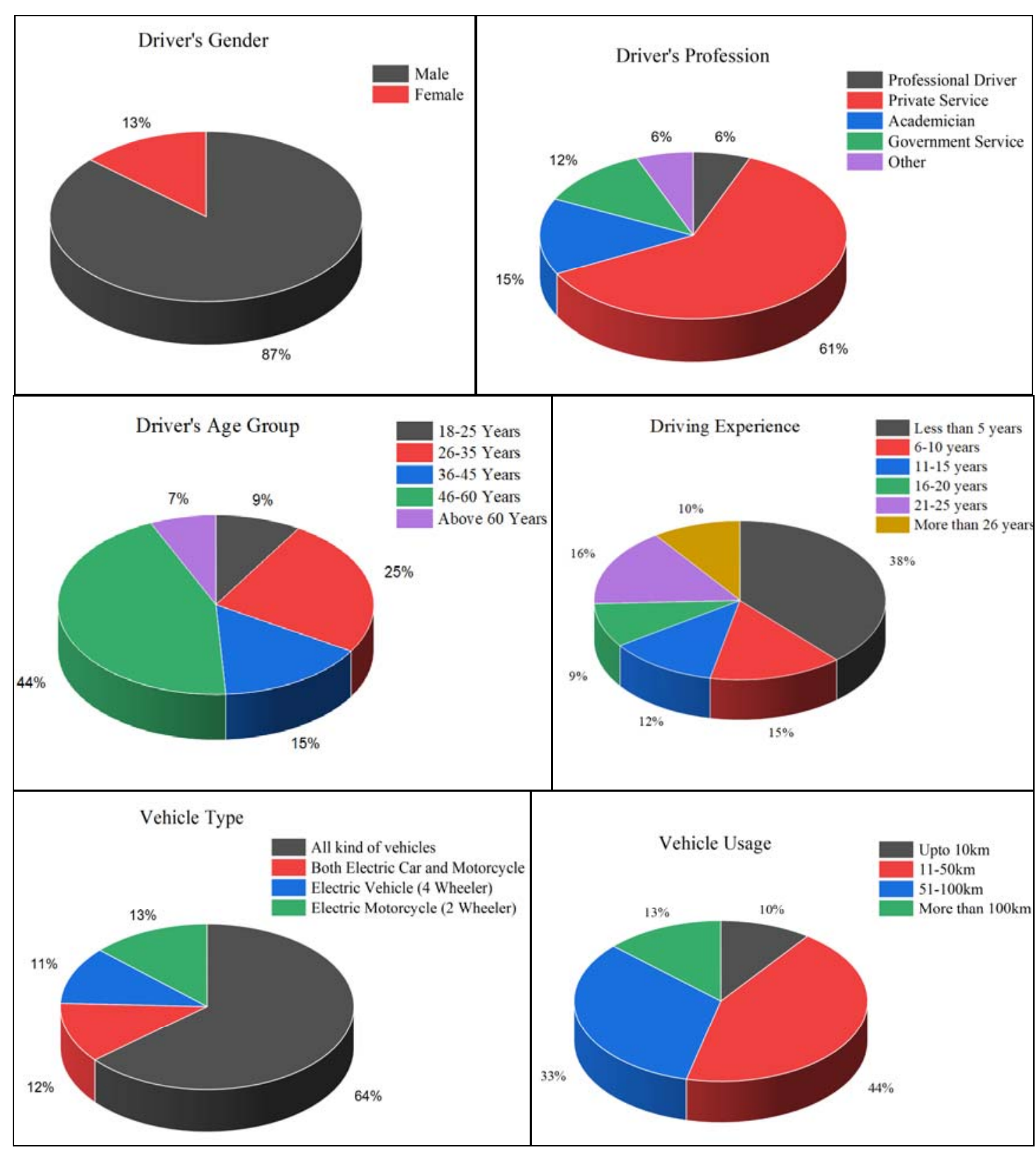

Fig. 4. Key attribute of the surveyed participants-Drivers (Sample Size 398)

\section{METHODOLOGY}

For analyzing the surveyed data, the scientific approach was employed to verify the statistical significant factors from the evaluator group. The systematic approach adopted in the present study has been explained in the current section.

\subsection{DBQ Survey}

One of the really popular ways of calculating conduct against safe driving is the Driver Behaviour Questionnaire (DBQ). The numerous researches utilized DBQ as a powerful tool to evaluate the significant factors related to safety and risk $[3,6,22]$. Interview questions have been incorporated into two parts. The first section of our interview questions was meant to capture the demographic features of participants such as age, gender, occupation, driving experience, and location as shown in Fig. 4. The structured approach to gathering quantitative data by a comprehensive DBQ survey contributes to reaching our primary step. DBQ data was collected from the drivers of different age groups with a deviation of driving experience in the second section of interview questions.

The technical records as well as the driver's recommendations were meticulously recorded in order to process them for analysis and interpretations. 


\subsection{Difficulties faced by drivers in various situations}

Risky driver behaviour due to difficulties faced by the driver is the primary cause of traffic incidences that poses a significant problem for public safety [25]. DBQ questionnaires contain 9 items of risky driver's behaviour situations related to the low noise of electric vehicle customized for the ease of predictive research on closed questions. Participants were asked about the level of risk encountered by them under varying potential circumstances, in particular when using electric cars with a six-point scale. The 9 items driver behaviour questionnaire (DBQ) items with assigned symbols and their significance for road safety are shown in Table 1. The questionnaires were chosen based on the results of previous similar studies performed by other researchers.

\subsection{Procedure}

A formal on-site interview was performed to collect technical evidence via comprehensive questionnaires which were the primary step in achieving the study goal. Their reactions have been cautiously studied for further analysis. The ANOVA analysis has been considered as most effective scientific tool for extensive interpretation the contributing factors [3]. Hence, the ANOVA approach was employed to evaluate the effects of contributing factors such as age, gender, driving experience in various situations mentioned in Table 1.

Table 1. A summary of previous studies related to possible difficulty faced by drivers

\begin{tabular}{|c|c|c|}
\hline Authors and Reference & $\begin{array}{l}\text { Description of our proposed } \\
\text { questions (Perceived Risk) }\end{array}$ & Findings and Remarks \\
\hline $\begin{array}{l}\text { M. del C. Pardo-Ferreira, J. C. } \\
\text { Rubio-Romero, F. C. Galindo- } \\
\text { Reyes, A. Lopez-Arquillos [6] }\end{array}$ & $\begin{array}{l}\text { Falling to identify the } \\
\text { presence of vehicle at start } \\
\text { of vehicle }(Q 1)\end{array}$ & $\begin{array}{l}\text { Difficulties faced by road users to get } \\
\text { updated with real start conditions of } \\
\text { electric vehicle. }\end{array}$ \\
\hline $\begin{array}{l}\text { M. Vollrath, T. Meilinger, H. P. } \\
\text { Krüger [26] }\end{array}$ & $\begin{array}{l}\text { While turning on the road, } \\
\text { the electric vehicle gets turn } \\
\text { off (Q2) }\end{array}$ & $\begin{array}{l}\text { Previous work was associated with } \\
\text { involvement of passengers affects the } \\
\text { likelihood of a conflict with that other car. }\end{array}$ \\
\hline $\begin{array}{l}\text { J. Parmar, P. Das, F. Azad, S. } \\
\text { Dave, R. Kumar [27] }\end{array}$ & At Parking of vehicle (Q3) & Evaluation of parking distinctiveness. \\
\hline $\begin{array}{l}\text { T. Richter, S. Ruhl, J. Ortlepp, E. } \\
\text { Bakaba and T. Richter, J. } \\
\text { Sachs }[28,29]\end{array}$ & $\begin{array}{l}\text { When overtaking one's own } \\
\text { vehicle by other passing } \\
\text { electric vehicle (Q4) }\end{array}$ & $\begin{array}{l}\text { Overtaking accidents are reports as a } \\
\text { significant factor for incidences on road. }\end{array}$ \\
\hline $\begin{array}{l}\text { S. Kulanthayan, W.K. Phang, K. } \\
\text { S. Hayati [30] }\end{array}$ & $\begin{array}{l}\text { At city traffic signals where } \\
\text { vehicle is stopped (Q5) }\end{array}$ & $\begin{array}{l}\text { Conflict during driving by green light } \\
\text { signal causes chance of accidents. }\end{array}$ \\
\hline $\begin{array}{l}\text { R. Fu, Y. Guo, W. Yuan, H. Feng, } \\
\text { Y. Ma [31] }\end{array}$ & At Road gradient (Q6) & $\begin{array}{l}\text { The traffic accident rate is affected with } \\
\text { the average gradient on } 2-3 \mathrm{~km} \text { sections } \\
\text { of descending road. }\end{array}$ \\
\hline U. Sandberg [32] & $\begin{array}{l}\text { While running the vehicle at } \\
\text { speed less than } 30 \mathrm{~km} / \mathrm{hr} \\
\text { (Q7) }\end{array}$ & $\begin{array}{l}\text { At speed higher than } 30 \mathrm{~km} / \mathrm{hr} \text {, tire noise } \\
\text { on the road is greater and tends to mask } \\
\text { the noise of the motor. }\end{array}$ \\
\hline $\begin{array}{l}\text { K. Sangkharat, J. E. Thornes, P. } \\
\text { Wachiradilok, F. D. Pope [21] }\end{array}$ & At rainy season (Q8) & $\begin{array}{l}\text { The possibilities of road accidents are } \\
\text { much more in rainy season. }\end{array}$ \\
\hline $\begin{array}{l}\text { A.K. Joshi, C. Joshi, M. Singh, V. } \\
\text { Singh [33] }\end{array}$ & At hill station (Q9) & $\begin{array}{l}\text { Road traffic accidents are more in the } \\
\text { hilly districts of the states in India. }\end{array}$ \\
\hline
\end{tabular}

\subsection{ANOVA}

Analysis of variance (ANOVA) is a set of mathematical models used for the analysis of the discrepancy in means and the related evaluation processes. The scientific study of the impact of parameters and their associated effects through the use of ANOVA allows researchers to recognize the most important influencing variables. The electric vehicles are noiseless operations, especially in running conditions. In quest of this, author's primary intention was to observe the significant effect of age group, gender and driving experience for considering the various possible situations of perceived risk faced by drivers. The young drivers with age 18 years to 
21 years are likely to involve in various risk situations [3]. Similarly, in adverse conditions, gender and driving expertise are very significant. Therefore, we comprehensively studied the effect of parameters such as gender, age, driving experience. F-value would be used to determine whether or not the element is correlated with the response attribute. F-statistic is based on the data of analysis and explains how far the deviation between the means reaches the expected likelihood.

\section{RESULTS AND DISCUSSION}

The results obtained from the comprehensive DBQ survey analysis are shown in Table 2. Almost all the participants show a positive response to acquire the related information based on their perceptions in the context of the quiet nature of electric vehicles. The majority of participants were male $(87 \%)$ whereas $13 \%$ women who reported their views. The age group considered for this research was segmented into two groups. Group A (young driver) consists of participants having an age less than or equal to 25 years whereas the remaining participants added in Group B (adult driver). Similarly, drivers were divided in order to analyze the discrepancy in value between them in terms of their driving experience. The descriptive statistics obtained from the current study are shown in Table 2.

Table 2. Results of driver's response adopted from different situations

\begin{tabular}{|c|c|c|c|c|c|c|c|c|c|}
\hline $\begin{array}{l}\text { Sr. } \\
\text { No. }\end{array}$ & $\begin{array}{l}\text { Situations at which drivers } \\
\text { behaviour examined (Perceived } \\
\text { Risk associated to following) }\end{array}$ & 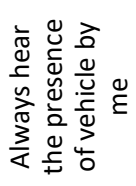 & 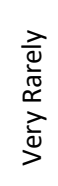 & 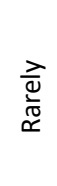 & 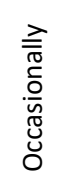 & 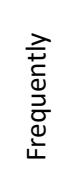 & 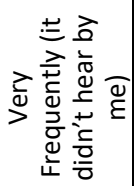 & 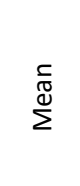 & 只 \\
\hline 1 & At starting of the electric vehicle & 29 & 65 & 58 & 52 & 111 & 83 & 4.01 & 2.00 \\
\hline 2 & $\begin{array}{l}\text { While turning on the road, the } \\
\text { electric vehicle gets turn off }\end{array}$ & 103 & 70 & 43 & 41 & 68 & 73 & 3.30 & 1.82 \\
\hline 3 & At Parking of vehicle & 88 & 67 & 45 & 49 & 66 & 83 & 3.47 & 1.86 \\
\hline 4 & $\begin{array}{l}\text { When other electric car } \\
\text { overtakes me }\end{array}$ & 32 & 67 & 57 & 52 & 106 & 84 & 3.97 & 1.99 \\
\hline 5 & $\begin{array}{l}\text { At city traffic signals where } \\
\text { vehicle is stopped }\end{array}$ & 29 & 55 & 52 & 50 & 94 & 118 & 4.20 & 2.05 \\
\hline 6 & At road gradient & 53 & 40 & 45 & 61 & 109 & 90 & 4.01 & 2.00 \\
\hline 7 & $\begin{array}{l}\text { While running the vehicle at } \\
\text { speed less than } 30 \mathrm{~km} / \mathrm{hr}\end{array}$ & 76 & 71 & 53 & 71 & 86 & 41 & 3.36 & 1.83 \\
\hline 8 & At rainy season & 47 & 56 & 56 & 40 & 94 & 104 & 3.98 & 2.00 \\
\hline 9 & At hill station & 21 & 51 & 52 & 73 & 108 & 93 & 4.19 & 2.05 \\
\hline
\end{tabular}

\subsection{Perception of Drivers}

Almost all respondents acknowledged that electric vehicles are difficult to hear; however, this increases satisfaction to passengers. The descriptive results obtained from study highlights the risk perception when other electric car overtakes nearby from one ( $N=242,60.80 \%)$. Furthermore, it was planned to evaluate the impact of various factors in view of the speed of the vehicle. Since the vehicle runs at higher speed on high ways, tyre tends to mask the noise which indicates the presence of the vehicle on road. However, it gets difficult to make out the presence for lower speed especially in the traffic region [32]. Consequently, our results are nearly matches with previous results related to difficulties in identifying the presence of vehicle at lower speed. In the rainy season, injuries and accidental cases are relatively high [21]. In line with this, our results suggest that drivers face multiple problems in the rainy season $(\mathrm{N}=238$, $59.79 \%$ ). Furthermore, in various driving conditions where it is impossible to hear the engine condition of electric vehicles at hill stations, drivers have found several difficulties (68.84\%) and reported as a perceived risk. Many drivers believe that driving an EV requires them to pay more attention than driving a conventional car. Still, electric vehicles are desirable because they make traveling more convenient and stressfree if you drive with precautious. 


\subsection{ANOVA Results}

Gender, driving experience, and age group are considered as very significant factor in adverse conditions as reported from past literature. Therefore, it was intended to study the effect of these comprehensive parameters such as gender, age, driving experience in a context of driver's risky behaviour based on their individual perception. F-value would be used to determine whether or not the element is associated with the response attribute. F-Statistic is based on the analysis data and explains how far the deviation between the means reaches the expected probability. Table 3 explains the detailed results from DBQ ANOVA analysis considering age group of driver. The measured F-value is found less than F-critical at every situation while considering age group as factor for analysis which would be evidence for relation that there are no statistical significant differences between age group.

The way of approach and responses in case of certain situations are prominently depends on gender of driver [34]. The results based on gender for various possible situations shows that risk associated with electric vehicle are different as per their gender involved in the research $(F$ meas. $=10.1171>$ Fcrit. $=3.8650$ and $p=0.000$ ). However, for other situations, the considerable difference was not reported. The results obtained from ANOVA study based on driver's gender is presented in Table 4.

Table 3. ANOVA analysis results based on driver's age

\begin{tabular}{|c|l|c|c|c|c|c|}
\hline $\begin{array}{c}\text { Sr. } \\
\text { No. }\end{array}$ & \multicolumn{1}{|c|}{$\begin{array}{c}\text { Situations at which drivers behaviour } \\
\text { examined (Perceived Risk associated to } \\
\text { following) }\end{array}$} & DF & MS & F & P Value & F-Critical \\
\hline 1 & At starting of the electric vehicle & 1 & 1.61309 & 0.6260272 & 0.42929 & 3.865048 \\
\hline 2 & $\begin{array}{l}\text { At turning on the road, the electric vehicle } \\
\text { gets turn off }\end{array}$ & 1 & 0.619568 & 0.173367 & 0.677362 & 3.865048 \\
\hline 3 & At Parking of vehicle & 1 & 0.009659 & 0.00275 & 0.958208 & 3.865048 \\
\hline 4 & When other electric car overtakes me & 1 & 0.143893 & 0.05404 & 0.816297 & 3.865048 \\
\hline 5 & At city traffic signals where vehicle is stopped & 1 & 0.532549 & 0.19491 & 0.659102 & 3.865048 \\
\hline 6 & At road gradient & 1 & 0.651472 & 0.224277 & 0.636061 & 3.865048 \\
\hline 7 & $\begin{array}{l}\text { While running the vehicle at speed less than } \\
\text { 30 km/hr }\end{array}$ & 1 & 5.773141 & 2.074846 & 0.150535 & 3.865048 \\
\hline 8 & At rainy season & 1 & 4.226589 & 1.384792 & 0.239993 & 3.865048 \\
\hline 9 & At hill station & 1 & 0.155593 & 0.067712 & 0.794832 & 3.865048 \\
\hline
\end{tabular}

Table 4. ANOVA analysis results based on driver's gender

\begin{tabular}{|c|l|c|c|c|c|c|}
\hline $\begin{array}{c}\text { Sr. } \\
\text { No. }\end{array}$ & \multicolumn{1}{|c|}{$\begin{array}{c}\text { Situations at which drivers behaviour } \\
\text { examined (Perceived Risk associated to } \\
\text { following) }\end{array}$} & DF & MS & F & P Value & F-Critical \\
\hline 1 & At starting of the electric vehicle & 1 & 1.487352 & 0.577158 & 0.44788 & 3.865048 \\
\hline 2 & $\begin{array}{l}\text { While turning on the road, the electric vehicle } \\
\text { gets turn off }\end{array}$ & 1 & 4.88434 & 1.370863 & 0.242368 & 3.865048 \\
\hline 3 & At Parking of vehicle & 1 & 34.65594 & 10.11716 & 0.000000 & 3.865048 \\
\hline 4 & When other electric car overtakes me & 1 & 8.474092 & 3.207854 & 0.074049 & 3.865048 \\
\hline 5 & At city traffic signals where vehicle is stopped & 1 & 0.069464 & 0.025413 & 0.873424 & 3.865048 \\
\hline 6 & At road gradient & 1 & 4.064996 & 1.40359 & 0.236834 & 3.865048 \\
\hline 7 & $\begin{array}{l}\text { While running the vehicle at speed less than } \\
\text { 30 km/hr }\end{array}$ & 1 & 0.534904 & 0.191333 & 0.662048 & 3.865048 \\
\hline 8 & At rainy season & 1 & 1.736606 & 0.567809 & 0.451579 & 3.865048 \\
\hline 9 & At hill station & 1 & 2.288522 & 0.998282 & 0.318337 & 3.865048 \\
\hline
\end{tabular}


The most important factors in risk behaviour are driving experience and age $[3,34]$. According to Table 5, the measured $F$ value is less than $F$ critical value in every possible situation considered for the study. It means that there is no statistical difference between groups of driving experience.

Furthermore, many drivers reported their views that the electric vehicles are difficult to identify especially at starting situations. Although the electric vehicle stands in rest position for starting situation, it would be the risk of accidents when someone tries to accelerate the vehicle at start mistakenly if they fail to identify the running state of the engine. Such scenarios should be thoroughly considered, especially at traffic signals where vehicles typically come to a halt with the engine turned off.

Engine braking is the act of decelerating a vehicle by releasing the accelerator and changing down by gears instead of using the footbrake. However, it cannot be possible in case of electric vehicles. Therefore, in numerous situations the vehicle speed may increase without will of driver/operator. Hence we emphasize to realize the risk associated with such situations. The results show that moderate risk is reported by many EV drivers, nevertheless, no evidence was found between contributing factors such as age group, gender, driving experience in regards to perceived risk.

Table 5. ANOVA analysis results based on driver's driving experience

\begin{tabular}{|c|l|c|c|c|c|c|}
\hline $\begin{array}{c}\text { Sr. } \\
\text { No. }\end{array}$ & \multicolumn{1}{|c|}{$\begin{array}{c}\text { Situations at which drivers behaviour } \\
\text { examined (Perceived Risk associated to } \\
\text { following) }\end{array}$} & \multicolumn{1}{|c|}{ DF } & MS & F & P Value & F-Critical \\
\hline 1 & At starting of the electric vehicle & 5 & 3.397353 & 1.325132 & 0.252514 & 2.237012 \\
\hline 2 & $\begin{array}{l}\text { While turning on the road, the electric } \\
\text { vehicle gets turn off }\end{array}$ & 5 & 0.473749 & 0.131387 & 0.985148 & 2.237012 \\
\hline 3 & At Parking of vehicle & 5 & 4.949542 & 1.419961 & 0.215988 & 2.237012 \\
\hline 4 & When other electric car overtakes me & 5 & 1.661003 & 0.622318 & 0.682856 & 2.237012 \\
\hline 5 & At city traffic signals where vehicle is stopped & 5 & 2.162542 & 0.791 & 0.556607 & 2.237012 \\
\hline 6 & At road gradient & 5 & 1.602414 & 0.549595 & 0.738638 & 2.237012 \\
\hline 7 & $\begin{array}{l}\text { While running the vehicle at speed less than } \\
\text { 30 km/hr }\end{array}$ & 5 & 3.282132 & 1.179054 & 0.318702 & 2.237012 \\
\hline 8 & At rainy season & 5 & 3.440845 & 1.128077 & 0.3448 & 2.237012 \\
\hline 9 & At hill station & 5 & 2.98264 & 1.306086 & 0.260444 & 2.237012 \\
\hline
\end{tabular}

\subsection{Discussion}

To meet today's rising demand for mobility in the era of technological advancement boosted the use of electric vehicles [9,35-38]. As the electric vehicles have a large number of added advantages, it is becoming popular in society. However, the certain possible difficulties and perceived risk due to noiseless running operations of electric vehicle cannot be neglected $[6,18,35]$. The present study is an attempt to highlight these future challenges. We thoroughly investigated the potential perceived risk in a variety of contexts where the perceived risk may be observed with the use of electric vehicles. It was reported that the perceived risk has been observed especially in parking conditions. As the F-measured value (10.1171) is greater than the Fcritical value (3.8650), the perceived risk has been observed statistically significant during parking of the electric vehicle considering gender as a prominent factor. There could be the numerous reasons for the same such as hurry during parking, getting late to reach in office and many more. The similar finding was also observed by other researchers with conventional vehicle type[6,34].

The various results obtained considering different situations like turning, overtaking, moving vehicle with less than $30 \mathrm{~km} / \mathrm{hr}$, and seasonal effects emphasizes that there is no significant difference considering age, gender, and driving level as the Fmeas.<Fcrit. for each case as shown in Table 3, Table 4 and Table 5 respectively. The numerous findings from previous articles were highlighted the certain issue related to low noise of electric vehicle are risky based on driver's or pedestrian's perception 
regarding road safety $[6,22,32,35]$; however, our results are something diverse particularly in parking situations based on driver's perceptions (Fmeas.=10.11716, p=0.0000, Fcrit.=3.865048).

For difficulty in identifying on-off conditions at start of electric vehicle, many participants express their views that EVs are trickier to recognize the state of start conditions (on-off engine state); however, no evidence was found related to statistical significant difference between age group ( $F=0.6260<F c r i t$ ), gender of drivers ( $\mathrm{F}=0.5771<\mathrm{F}$ crit.) and driving experience ( $F=1.325132<$ Fcrit.). For improved vehicle performance, some drivers behaviour under naturalistic driving circumstances were investigated [36]. Consequently, to realize the numerous practices followed by drivers, the perception of driver's behaviour related to getting the moving vehicle turned off while turning the vehicle on the road was examined in the context of age, gender, and driving experience. The findings from the present study show no significant difference in case of age, gender and driving experience respectively. ( $F=0.173367, F=1.370863, F=0.1313$ ). In the case of traffic signals, the risks of collisions are greater [37]. Therefore, it was planned to evaluate the difficulties and risk faced by drivers to identify the nature of EVs. Moreover, the findings elaborates that there is no significant difference between age ( $F=0.19491<F c r i t$.$) gender$ ( $F=0.025413<F c r i t$.) and driving experience ( $F=0.7910<$ Fcrit.).

Finally, Overall outcome from the current study shows the moderate level of difficulties associated with quiet nature of electric vehicles which cannot be avoided in certain conditions like overtaking of vehicles. At the same time, the additional anonymous sound would not be a good option for the vehicle's noiseless trait [32], thereby, recommendations stand to need of advanced control strategy to tackle such kind of difficulties for better safety of electric vehicles.

\section{CONCLUSIONS}

In this study, the perceived risk associated with detection of vehicle presence due to low electric vehicle noise was examined on the basis of the results obtained from comprehensive study conducted among 398 drivers in Mumbai. Drivers Behaviour Questionnaires (DBQ) tool was successfully employed with ANOVA approach to reveal the significant factors like age of driver, gender of driver, and driving experience. The outcome of the present study is appended briefly as follows:

- The various results obtained considering different situations like turning, overtaking, moving vehicle with less than $30 \mathrm{~km} / \mathrm{hr}$, and seasonal effects emphasizes that there is no significant difference considering age, gender, and driving level as the Fmeas.<Fcrit. for each case as shown in Table 3, Table 4 and Table 5 respectively.

- The identifying presence of the electric vehicle is moderately difficult for parking situations. The factors like age and driving experience have no significant relationship in the context of parking; however, the perceived risk is associated with gender difference especially for parking the vehicle.

The outcome of this study would make it easier for electric car drivers to understand specific challenges. In addition, it will aid to design a specific mechanism which would be prominent solution for parking of vehicle due to low noise characteristics of electric vehicles.

\section{ACKNOWLEDGMENTS}

Authors are thankful to Technical Education Quality Improvement Programme (TEQIP-III) in Veermata Jijabai Technological Institute (VJTI), Mumbai, India for awarding financial assistantship to corresponding author.

\section{REFERENCES}

[1] V. Gijre, S. Gupta, Urban transport governance practice and challenges in an emerging economy - case study of India. Transportation Research Procedia, 48, 2020: 2435-2445.

https://doi.org/10.1016/i.trpro.2020.08.293

[2] N.A.B. Mabahwi, O.L.H. Leh, D. Omar, Human health and wellbeing: human health effect of air pollution. Procedia - Social and Behaviour al Sciences, 153, 2014: 221-229.

https://doi.org/10.1016/i.sbspro.2014.10.056

[3] D. Farooq, J. Juhasz, Statistical Evaluation of Risky Driver Behaviour Factors that Influence Road Safety based on Drivers Age and Driving Experience in Budapest and Islamabad. European Transport, 80 (2), 2020: 1-18.

[4] J. Jagnoor, S. Prinja, H. Nguyen, B.J. Gabbe, M. Peden, R.Q. Ivers, Mortality and healthrelated quality of life following injuries and associated factors: a cohort study in 
Chandigarh, North India. Injury Prevention, 26 (4), 2020: 315-323.

https://doi:10.1136/injuryprev-2019-043143

[5] L.N. Patil, H.P. Khairnar, Investigation of human safety based on pedestrian perceptions associated to silent nature of electric vehicle. Evergreen, 08 (02), 2021: 0000.

[6] M. del C. Pardo-Ferreira, J.C. Rubio-Romero, F.C. Galindo-Reyes, A. Lopez-Arquillos, Work-related road safety: The impact of the low noise levels produced by electric vehicles according to experienced drivers. Safety Science, 121, 2020: 580-588.

https://doi.org/10.1016/i.ssci.2019.02.021

[7] A. Pandey, M. Brauer, M. L. Cropper, K. Balakrishnan, P. Mathur, S. Dey, B. Turkgulu, G. A. Kumar, M. Khare, G. Beig, T. Gupta, Health and economic impact of air pollution in the states of India: the Global Burden of Disease Study 2019. The Lancet Planetary Health, 5 (1), 2021: e25-e38.

[8] B. Sudhakara Reddy, P. Balachandra, Urban mobility: A comparative analysis of megacities of India. Transport Policy, 21, 2012: 152-164.

https://doi:10.1016/j.tranpol.2012.02.002

[9] V. Gulati, National electric mobility mission plan 2020, Department of Heavy Industry. Ministry of Heavy Industries \& Public Enterprises, Government of India, 2012.

[10] H. He, C. Wang, H. Jia, X. Cui, An intelligent braking system composed single-pedal and multi-objective optimization neural network braking control strategies for electric vehicle. Applied Energy, 259, 2020: 114172.

\section{https://doi:10.1016/j.apenergy.2019.114172}

[11] L. Steinbach, M. E. Altinsoy, Influence of an artificially produced stationary sound of electrically powered vehicles on the safety of visually impaired pedestrians. Applied Acoustics, 165, 2020: 107290.

https://doi:10.1016/j.apacoust.2020.107290

[12] A. Dwarakanath, M. W. Elliott, Assessment of Sleepiness in Drivers. Sleep Medicine Clinics, 14 (4), 2019: 441-451.

https://doi:10.1016/i.jsmc.2019.08.003

[13] V. Gitelman, F. Pesahov, R. Carmel, Speed perception by drivers as dependent on urban street design; a case-study. ToTS, 11 (2), 2020: 5-18.

https://doi:10.5507/tots.2020.002

[14] S. Velmurugan, S. Padma, E. Madhu, S. Anuradha, S. Gangopadhyay, A study of factors influencing the severity of road crashes involving drunk drivers and non drunk drivers. Research in Transportation Economics, 38 (1), 2013: 78-83.

https://doi:10.1016/j.retrec.2012.05.01

[15] Y.J. Yasin, M. Grivna, F.M. Abu-Zidan, Reduction of pedestrian death rates: a missed global target. World J Emerg Surg, 15 (1), 2020.

https://doi:10.1186/s13017-020-00315-2

[16] NHTSA, National Motor Vehicle Crash Causation Survey: Report to Congress. NHTSA, 2008, p.47.

[17] P. Papaioannou, Driver behaviour, dilemma zone and safety effects at urban signalised intersections in Greece. Accident Analysis \& Prevention, 39 (1), 2007: 147-158.

https://doi:10.1016/j.aap.2006.06.014

[18] Q. Yuan, H. Yang, J. Huang, S. Kou, Y. Li, A. Theofilatos, What factors impact injury severity of vehicle to electric bike crashes in China?. Advances in Mechanical Engineering, 9 (8), 2017: 168781401770054.

https://doi:10.1177/1687814017700546

[19] European Commission (2016), Annual Accident Report. European Commission, Directorate General for Transport. European Commission, 2016.

[20] F. Ekman, M. Johansson, M. Karlsson, H. Strömberg, L.-O. Bligård, Trust in what? Exploring the interdependency between an automated vehicle's driving style and traffic situations. Transportation research part F: traffic psychology and behaviour, 2021: p.13.

[21] K. Sangkharat, J. E. Thornes, P. Wachiradilok, and F. D. Pope, Determination of the impact of rainfall on road accidents in Thailand. Heliyon, 7 (2), 2021: e06061.

https://doi:10.1016/i.heliyon.2021.e06061

[22] Y. Park, M. Garcia, Pedestrian safety perception and urban street settings. International Journal of Sustainable Transportation, 14 (11), 2020: 860-871.

https://doi:10.1080/15568318.2019.1641577

[23] C. Cabrera-Arnau, R. Prieto Curiel, S. R. Bishop, Uncovering the behaviour of road accidents in urban areas. Royal Society open science, 7 (4), 2020: 191739.

https://doi:10.1098/rsos.191739

[24] D. Mahata, P.K. Narzary, D. Govil, Spatiotemporal analysis of road traffic accidents in Indian large cities. Clinical Epidemiology and Global Health, 7 (4), 2019: 586-591.

https://doi:10.1016/i.cegh.2019.01.005 
[25] J.M. Lyman, G. McGwin, R.V. Sims, Factors related to driving difficulty and habits in older drivers. Accident Analysis \& Prevention, 33 (3), 2001: 413-421.

https://doi:10.1016/S0001-4575(00)00055-5

[26] M. Vollrath, T. Meilinger, H. P. Krüger, How the presence of passengers influences the risk of a collision with another vehicle. Accident Analysis \& Prevention, 34 (5), 2002: 649-654.

https://doi:10.1016/S0001-4575(01)00064-1

[27] J. Parmar, P. Das, F. Azad, S. Dave, R. Kumar, Evaluation of Parking Characteristics: A case study of Delhi. Transportation Research Procedia, 48, 2020: 2744-2756.

https://doi:10.1016/i.trpro.2020.08.242

[28] T. Richter, S. Ruhl, J. Ortlepp, E. Bakaba, Causes, consequences and countermeasures of overtaking accidents on two-lane rural roads. Transportation Research Procedia, 25, 2017: 1989-2001.

https://doi:10.1016/j.trpro.2017.05.395

[29] T. Richter, J. Sachs, Turning accidents between cars and trucks and cyclists driving straight ahead. Transportation Research Procedia, 25, 2017: 1946-1954.

https://doi:10.1016/j.trpro.2017.05.219

[30] S. Kulanthayan, W. K. Phang, K. S. Hayati, Traffic light violation among motorists in malaysia. IATSS Research, 31 (2), 2007: 6773.

https://doi:10.1016/S0386-1112(14)60224-7

[31] R. Fu, Y. Guo, W. Yuan, H. Feng, and Y. Ma, The correlation between gradients of descending roads and accident rates. Safety Science, 49 (3), 2011: 416-423. https://doi:10.1016/j.ssci.2010.10.006

[32] U. Sandberg, Adding noise to quiet electric and hybrid vehicles: An electric issue. Acoustics Australia, 2012, p.10.

[33] A.K. Joshi, C. Joshi, M. Singh, V. Singh, Road traffic accidents in hilly regions of northern India: What has to be done?. World Journal of Emergency Medicine, 5 (2), 2014: 112115.

https://doi:10.5847/wjem.j.issn.1920-8642.2014. $\underline{02.006}$

[34] M. F. Hichim, A. S. Khusheef, S. Hasan, The Effects of Driver Age and Gender on Vehicle Stopping Distance Under Different Speeds. European Transport, 80 (1), 2020: p.11.

[35] L. Maffei, M. Masullo, Electric Vehicles and Urban Noise Control Policies. Archives of Acoustics, 39 (3), 2015: 333-341.

https://doi:10.2478/aoa-2014-0038

[36] H. Singh, A. Kathuria, Analyzing driver behaviour under naturalistic driving conditions: A review. Accident Analysis \& Prevention, 150, 2021: 105908.

https://doi:10.1016/i.aap.2020.105908

[37] I. Dirnbach, T. Kubjatko, E. Kolla, J. Ondruš, Ž. Šarić, Methodology designed to evaluate accidents at intersection crossings with respect to forensic purposes and transport sustainability, Sustainability, 12 (5), 2020: 1972.

https://doi.org/10.3390/su12051972

[38] L. N. Patil, H. P. Khairnar, Assessing Impact of Smart Brake Blending to Improve Active Safety Control by Using Simulink. Applied Engineering Letters, 6 (1), 2021: 29-38.

https://doi:10.18485/aeletters.2021.6.1.4 